\title{
Greve como luta por direitos: as paralisações dos cocheiros e carroceiros no Rio de Janeiro (1870-1906) ${ }^{1}$
}

\author{
Strikes and struggles for rights: the coachmen \\ and carters stoppages in Rio de Janeiro (1870-1906)
}

Paulo Cruz Terra*

\section{Resumo}

Tendo em vista que as greves constituíram importante via de luta por aquilo que os trabalhadores consideravam seus direitos, o objetivo do artigo é justamente analisar as paralisações realizadas pelos cocheiros e carroceiros no Rio de Janeiro, entre 1870 e 1906 . Nesse período, os trabalhadores do transporte formaram a categoria que mais empreendeu greves na capital do país, e suas paredes surgem como importantes esferas para entendermos que direitos estavam sendo pleiteados e as vias utilizadas para alcançá-los.

Palavras-chave: greves; direitos; Rio de Janeiro; transporte.

\section{Abstract}

Considering that the strikes constituted important means of struggle for what workers considered as their rights, the purpose of this paper is to analyze the stoppages made by coachmen and carters in Rio de Janeiro, between 1870 and 1906. During this period, transport workers formed the category that made more strikes in the Brazil's capital, and its stoppages appear as important spheres to understand what rights were being required, and the ways used to achieve them.

Keywords: strikes; rights; Rio de Janeiro; transport.

A garantia de direitos por parte do Estado brasileiro foi bem precária, tanto no Império quanto na Primeira República. Os direitos políticos, tidos como o direito de eleger e ser eleito para cargos políticos, eram restritos a uma pequena parcela da população. Medidas como a exclusão dos analfabetos do direito de votar, instituída em 1881 e mantida na primeira Constituição republicana, diminuíram ainda mais a participação popular nas eleições. ${ }^{2}$

\footnotetext{
* Pós-doutorando, Programa de Pós-Graduação em História, Universidade Federal Fluminense (UFF). p003256@yahoo.com.br
} 
No que diz respeito aos direitos civis, uma mudança substancial foi a abolição da escravidão, em 1888. Entretanto, medidas como a exclusão do voto aos analfabetos e a perseguição à vadiagem, prevista no Código Penal de 1890, estavam associadas principalmente ao controle dos egressos do cativeiro.

As garantias de direitos sociais por parte do governo eram praticamente nulas, tendo ocorrido um retrocesso na primeira Constituição republicana ao se retirar do Estado a obrigação de fornecer educação primária. Contudo, o governo federal chegou a aprovar alguns direitos para os trabalhadores, principalmente a partir do final da década de 1910. O contato entre Estado e trabalhadores ocorria também na violenta repressão policial aos movimentos destes e à ociosidade, já que o trabalho se tornou, no discurso político governamental, "uma atividade saneadora e mobilizadora necessária à manutenção da ordem social" (Gomes, 2005, p.300).

Diante de um cenário de tanta precariedade e restrições aos direitos, e tendo em vista que muitos estavam praticamente excluídos da política oficial - não eram nem eleitores nem eleitos -, quais as formas utilizadas pela população para se fazer ouvir? No que diz respeito aos trabalhadores, especificamente, as greves constituíram importante via de luta pelo que eles consideravam seus direitos. ${ }^{3} \mathrm{O}$ objetivo do presente artigo é justamente analisar as paralisações realizadas pelos cocheiros no Rio de Janeiro, entre 1870 e 1906. Nesse período, os trabalhadores do transporte formaram a categoria que mais empreendeu greves na capital do país, e suas paredes surgem como importantes esferas para entendermos que direitos estavam sendo pleiteados e as vias utilizadas para alcançá-los.

Entre 1873, data da primeira greve dos cocheiros e carroceiros, e 1906, ${ }^{4}$ os trabalhadores do transporte realizaram 22 paralisações. Em relação ao número de greves, em segundo lugar vieram os tecelões com 16, seguidos pelos sapateiros, com 11. Embora tenham empreendido o maior número de paredes no Rio de Janeiro, as suas mobilizações foram apenas citadas pelos estudos que trataram das greves nessa cidade. ${ }^{5}$

As paralisações dos cocheiros e carroceiros estavam relacionadas a importantes transformações no setor de transporte, ocorridas a partir da segunda metade do século XIX. Esse foi um período em que as mais variadas mercadorias - desde o café, principal produto de exportação do Brasil, até o lixo das residências - deixaram de ser transportadas pelos carregadores negros, em sua maioria escravos, e passaram a ficar a cargo das carroças. Foi ainda nesse período que surgiram os primeiros bondes, que logo se tornaram o principal meio de locomoção da população do Rio de Janeiro. 
No que diz respeito às motivações das greves, um importante elemento que levou cocheiros e carroceiros a paralisarem o trabalho foram as constantes leis e regulamentos a que eram submetidos. De um total de 22 paralisações da categoria, cinco $(22,7 \%)$ tiveram como principal motivo as leis, em âmbito federal e municipal, e regulamentos policiais. Das três principais paredes (em 1890,1900 e 1906), por congregarem o maior número de trabalhadores, duas $(66,66 \%)$ estavam atreladas às leis e regulamentos.

Se o Estado, antes da legislação trabalhista, não regulava o trabalho dentro do espaço privado das fábricas, o mesmo não se pode dizer daqueles que exerciam seus ofícios na esfera pública. Pelas condições inerentes à profissão, cocheiros e carroceiros viviam longe dos olhos de um patrão, até porque muitas vezes trabalhavam por conta própria (Azevedo, 2009, p.79). Além do esquema de fiscalização das próprias empresas do transporte, que foi se aperfeiçoando ao longo do tempo, os trabalhadores do setor foram objeto e estiveram em contato com um amplo universo de leis e regulamentos, que procuravam controlá-los.

Em dezembro de 1872, a Câmara Municipal do Rio de Janeiro assinou um contrato com a empresa Nunes de Souza \& Cia. para que esta fizesse a remoção de lixo das residências, substituindo assim cerca de 120 carroceiros que trabalhavam por conta própria nesse serviço. No decorrer de 1873, houve uma enorme polêmica sobre esse contrato, tendo como principal opositor Luiz Fortunato Filho, advogado dos carroceiros que realizavam o serviço anteriormente. Ele alegou, em diversas cartas publicadas nos periódicos e em requerimentos enviados às autoridades competentes, que tal empresa representaria o monopólio do serviço, contrariando assim a liberdade de indústria e a liberdade de os próprios moradores escolherem pessoas de sua confiança para realizar a tarefa. ${ }^{6}$

A Câmara Municipal, como forma de instituir o monopólio, deixou de conceder as licenças para que os carroceiros de lixo exercessem seu ofício e apreendeu os veículos daqueles que continuaram a trabalhar. Diante do lixo que se acumulava nas ruas - em parte porque a empresa não deu conta da demanda; em parte porque alguns moradores se recusaram a contratar o seu serviço -, a Câmara decidiu conceder as licenças novamente aos carroceiros. Estes, por sua vez, se recusaram a voltar ao trabalho alegando que a licença era condicional e poderia ser removida a qualquer momento. Estava declarada uma greve objetivando que a instituição camarária lhes garantisse o direito de trabalhar. ${ }^{7} \mathrm{O}$ Ministério dos Negócios do Império expediu uma portaria indicando que, enquanto a empresa não tivesse o material necessário para a 
execução do contrato, a licença para os carroceiros deveria ser mantida "independente da designação das casas a que cada carroça pode servir". ${ }^{8}$ Os carroceiros decidiram, então, voltar a trabalhar.

A empresa acabou não cumprindo o contrato e os carroceiros continuaram a exercer o seu ofício. Em 1875, a Câmara aprovou uma série de regras para as carroças que removiam lixo, das ruas e das casas da cidade. Essa instituição tentava cercear e controlar ainda mais aqueles trabalhadores que haviam lhe afrontado. Estavam previstos os locais em que os condutores dos veículos poderiam descarregar o lixo, o modelo da carroça e também que o serviço de remoção deveria ser feito "somente até às 9 horas da manhã, nos meses de Outubro a Março, e até às 10, nos de Abril a Setembro". A punição para a infração de qualquer uma das disposições seria "a multa de $30 \$$ e a prisão de oito dias, dobradas em caso de reincidência” (Código de Posturas..., 1894, p.231-232).

Em fevereiro de 1876, a Câmara expediu uma portaria exigindo a rigorosa execução da postura que estipulava o horário máximo da retirada do lixo. As consequências da referida postura, como as multas, foram consideradas injustas pelos trabalhadores, que tiveram ainda as carroças levadas para o depósito, fato apontado como sem lei que o autorizasse. Esses elementos, aliados à limitação do serviço até as horas da manhã, levaram os carroceiros a realizarem nova parede. O que estava em jogo, nas palavras do advogado Luiz Fortunato Filho, era o direito ao trabalho.

Os carroceiros que atuavam no recolhimento do lixo eram, em sua maioria, trabalhadores autônomos, e essa característica foi muito frisada na imprensa a favor deles. Na Gazeta de Notícias, do dia 15 de fevereiro de 1876, foi exposto:

Tem a Câmara algum contrato com os carroceiros que removem o lixo das casas particulares? Concede-lhes alguma garantia? Não, obriga deles que paguem uma licença ... com impostos, multas, prisões, depósitos. Como pretende agora impor leis a homens livres, que hão de trabalhar se quiserem? Como impor um dever àqueles [a] que não concedem direitos?

Nessa argumentação está a ideia de que os carroceiros só possuíam deveres, como licenças e impostos, e em contrapartida a Câmara não lhes assegurava nenhum direito. Seguindo esse raciocínio, a Gazeta afirmou que a Câmara não previu a hipótese de que os carroceiros não se sujeitariam às imposições 
dessa instituição, porque ela não tinha o direito de fazê-las, e teriam dito os trabalhadores:

o serviço feito desse modo não nos pode deixar vantagem, e nós não estamos encarregados de velar pela higiene da cidade; trabalhamos para ganhar o pão que comemos; se quiserem que continuemos a trabalhar como trabalhamos, continuaremos; senão, não. ${ }^{10}$

A greve ganhou bastante repercussão nos periódicos porque o lixo que deixou de ser recolhido das casas foi associado ao aumento do número, já assustador, de mortes por febre amarela. O ostensivo apoio da imprensa, o lixo acumulado pelas ruas e o aumento dos casos de febre amarela fizeram que os carroceiros saíssem mais uma vez vitoriosos. Segundo a Revista Illustrada, em 19 de fevereiro de 1876, "afinal a Câmara Municipal, a polícia e o Ministério do Império tiveram de dar mãos à palmatória da nobre classe carroceiral”, e a postura acabou sendo revogada. ${ }^{11}$ Ironicamente, logo após o fim da greve, a Câmara, que saiu derrotada, voltou a discutir a possibilidade de uma empresa monopolizar o serviço de retirada do lixo das casas particulares. Naquele momento era mais importante do que nunca que o serviço não continuasse nas mãos daqueles carroceiros que tinham sido sucessivamente vitoriosos, e que conseguiram frear as tentativas da Câmara de controlar e até mesmo suprimir o seu trabalho.

A primeira greve organizada pelos trabalhadores do transporte urbano no período republicano estava relacionada ao Código Penal, promulgado em 11 de outubro de 1890. O fato de este Código ter entrado em vigência antes mesmo da primeira Consituição Federal Republicana, que vigorou a partir de 24 de fevereiro de 1891, é bastante significativo e aponta uma preocupação dos dirigentes republicanos com a ordem e o controle sobre a população.

Grande parte dos jornais cariocas afirmou que os cocheiros e carroceiros não reclamavam aspectos presentes no Código. As alegações desses trabalhadores foram consideradas pelo Jornal do Commercio, por exemplo, como fantasiosas, e deveriam, portanto, ter sido malevolamente inventadas "por especuladores miseráveis, que vivem da simplicidade dos trabalhadores" e teria causado séria impressão no espírito "dócil dos pobres cocheiros". ${ }^{12}$ Essa imagem de que os trabalhadores seriam apenas uma peça usada por uma trama bem maior apareceu em outras folhas diárias.

A voz dissonante nesse contexto foi a edição do dia 2 de dezembro de 1890 da Gazeta da Tarde. Esse periódico indicou que uma comissão de carroceiros 
se dirigiu ao escritório do jornal e mostrou que não estava armada de tão pouca razão, "como geralmente se supõe, pois se não existe a tal postura de que tanto se falou ontem, existem na reforma judiciária do Sr. Campos Salles as seguintes draconianas disposições, contra as quais se rebelaram os carroceiros". ${ }^{13} \mathrm{~A}$ comissão teria citado dois artigos do Código referentes à punição dos acidentes.

A passagem da Gazeta da Tarde, citada anteriormente, permite visualizar os carroceiros não apenas como manipuláveis e ludibriados por forças que os usavam para alcançar motivos maiores. Pelo contrário, a comissão que foi ao jornal indica que eles eram sujeitos ativos e conscientes de suas demandas, e que sabiam, sim, contra o que lutavam, e por que o faziam. Ao apontarem exatamente os artigos a que iam contra, os trabalhadores desmentiam a afirmação publicada no jornal Diário de Notícias de que não era o Código Penal o que os cabeças da greve argumentavam, "principalmente porque o código ainda é pouco conhecido, mesmo por parte da gente letrada do país". ${ }^{14}$

Embora vários textos nos jornais tentassem apontar que o artigo do novo Código Penal não dizia respeito unicamente aos cocheiros e carroceiros, estes consideraram que lhes atingia. Os acidentes envolvendo veículos eram constantes e representavam um dos maiores pontos de conflito entre os trabalhadores e os usuários, sendo os primeiros acusados e altamente detratados pela imprensa. Em 1890, particularmente, havia ocorrido um atropelamento de uma criança, que causou grande comoção e protesto da população. ${ }^{15}$ Era, portanto, uma preocupação real para os que conduziam os carros qualquer lei que incidisse sobre esse aspecto.

Outro argumento utilizado para desqualificar a greve era de que o artigo não representava uma novidade em relação à legislação do período imperial. A proclamação da República teve impacto no movimento operário carioca e representou o despertar de anseios e expectativas de participação política. Por mais que não fosse novo, naquele momento específico o Código Penal significou uma oportunidade de os cocheiros e carroceiros manifestaram-se na nova ordem, por meio da greve. É importante frisar que essa foi a primeira paralisação que reuniu praticamente toda a categoria, incluindo os cocheiros e carroceiros que trabalhavam nas empresas e também por conta própria.

Além de afirmarem que os trabalhadores estavam sendo manipulados na referida greve, alguns órgãos da imprensa questionaram ainda a motivação da parede em si. Segundo o Diário de Notícias: "Em toda a parte do mundo há penas no código criminal para os delitos de toda a natureza e nunca houve greves contra a lei que é mantida pelos governos". ${ }^{16}$ Ao opinar sobre a mesma 
paralisação, o Jornal do Commercio expôs que: “Uma parede de operários tem por fim conseguir a reparação de um agravo ou um aumento de salário. Neste conluio, porém, os carroceiros e cocheiros não tinham fito algum determinado".${ }^{17}$ As citações parecem exprimir a ideia de que, de forma geral, a oposição a um regulamento ou lei não eram razões habituais e justas para uma parede. Considerava-se, assim, que as paralisações fossem feitas com o intuito de obter um aumento salarial ou receber pagamentos atrasados.

Alguns jornais, porém, podiam apresentar uma imagem diversa. Esse foi o caso da Gazeta da Tarde, que reproduziu um trecho de uma notícia do periódico Nova Pátria sem nenhum comentário, o que mostra que endossava as afirmações feitas por esse jornal sobre as causas da parede dos cocheiros:

Desde que a força do direito foi substituída pelo direito da força; desde que a cada momento se calça aos pés a lei e as normas comezinhas da administração; desde que o povo se acha representado por um congresso de designados, sem autoridade para fazer justiça ou exigir reparação; desde que o povo se convenceu de que as leis que lhe são impostas não emanam da vontade popular, mas de uma camarilha que se conserva no poder pelo único prestígio da força, e de que esses decretos vêm em socorro de interesses nem sempre confessáveis - desapareceu este freio que, de par com a religião, peia as comoções populares e que se chama - o respeito consciente à lei. ${ }^{18}$

Essa passagem é uma interpretação interessante sobre as greves relacionadas às leis. Aponta as diferentes razões que levaram os trabalhadores a deixarem de ver as leis e as normas com respeito servil, como a de que elas emanavam da vontade de um grupo restrito e de que serviam a interesses "nem sempre confessáveis". Ao desmitificarem as leis e normas, os trabalhadores podiam e deviam vê-las como arenas em que deveriam lutar.

A parede iniciada em 15 de janeiro de 1900, por sua vez, teve como estopim o regulamento da Polícia sobre o setor de transporte de veículos e seus trabalhadores, expedido em dezembro de 1899. A própria data em que estourou a greve estava relacionada com esse regulamento, já que o dia 15 era o último prazo para que os trabalhadores cumprissem as determinações.

O jornal Gazeta de Notícias apontou que a parede foi consequência da falta de esclarecimentos prévios, por parte da Polícia, de detalhes do novo regulamento. Segundo o periódico, não era possível compreender por que aquela instituição não se pronunciava a respeito do boato que corria de que os cocheiros seriam fotografados por essa instituição. ${ }^{19}$ 
Apesar de o governo ter tratado a obrigação da fotografia como boato, o Jornal do Brasil expôs que para os trabalhadores essa era uma exigência real. Embora não estivesse presente no regulamento, os cocheiros alegaram que algumas empresas, como a São Christovão, afixaram boletins impondo a fotografia para identidade do trabalhador, e que a inspetoria de veículo também a exigia. $^{20}$

A obrigatoriedade da fotografia foi uma questão de fato no período da greve, o que levou, por exemplo, o Chefe de Polícia a lançar, logo no primeiro dia da greve, um boletim deixando claro que o novo regulamento de inspeção de veículos não "determina que os cocheiros sejam fotografados" ${ }^{21}$ Um estúdio fotográfico da cidade aproveitou a situação e propagou que a solução do governo ante a greve, na parte que obrigava os cocheiros a tirarem retratos na Polícia, era "dar-lhes plena a liberdade de escolha de seus fotógrafos". ${ }^{22}$

Mas por que deixar-se fotografar na Polícia era considerado pelos trabalhadores como algo ruim? Todos os jornais indicaram que esse era um procedimento dispensado, até então, aos gatunos. O Jornal do Brasil expôs que um funcionário do serviço de antropometria da Polícia escreveu que a foto servia justamente para identificação, para que o sujeito não aparecesse com qualquer nome que lhe ocorresse. ${ }^{23}$ Dessa forma, ao serem obrigados a tirar retratos, os cocheiros se viam comparados aos larápios.

A demanda dos cocheiros pelo fim da exigência da fotografia estava ligada, portanto, ao aspecto simbólico que essa representava. Se para as autoridades ela era apenas uma proposta infundada - já que a fotografia não constava no texto do regulamento -, os trabalhadores alegaram que ela era sim exigida pelas companhias, e até mesmo pela inspetoria de veículos.

Após o término da paralisação, no dia 17 de janeiro, a Sociedade União Beneficente e Protetora dos Cocheiros entregou ao Ministro da Justiça um documento contendo demandas da categoria. O próprio texto da petição apresentou que essa defesa de interesses ia além "dos limitados fins definidos em seus estatutos”. Essa associação foi criada em 17 de abril de 1881, e constava no seu estatuto a função de "socorrer os associados e suas famílias". ${ }^{24}$

A petição entregue pelos trabalhadores comentava diversos aspectos do regulamento policial, como o artigo 36, que determinava a remissão do veículo para o Depósito Público. Alegou-se não ser justo os cocheiros e carroceiros serem duplamente punidos, pois além de terem suas carteiras apreendidas, a remoção do veículo acarretaria despesas para a sua retirada. No que diz respeito à obrigação de os trabalhadores darem aviso prévio de oito dias quando pretendessem retirar-se do serviço, o requerimento alegou que essa era uma 
determinação que já existia, e que o novo regulamento instituía a mesma medida em relação aos patrões. A deliberação, entretanto, não poderia permanecer, pois os trabalhadores estavam "habituados ao império da liberdade" e a prova era que, "embora em vigor, nunca foi executada". ${ }^{25}$

A petição trazia ainda a denúncia de extorsões por parte da Inspetoria de Veículos na cobrança dos emolumentos previstos. Segundo o documento, era feita uma cobrança de $20 \$$ a mais do que aquilo a que eram obrigados, já que o artigo 13 previa o pagamento de $5 \$$ de matrícula para os condutores de carros de quatro rodas e $3 \$$ para qualquer outro. Contra essa exigência ilegal, alguns interessados reclamaram o cumprimento da lei junto ao $1^{\circ}$ Delegado Auxiliar. Este, por sua vez, teria reduzido a taxa a $12 \$ 500$, o que ainda excedia ao estabelecido.

Após a denúncia, feita pelo documento da associação dos cocheiros, de cobranças indevidas por parte da inspetoria de veículos, os periódicos noticiaram amplamente o escândalo. No dia 19 de janeiro, o Jornal do Commercio publicou na íntegra o requerimento dos cocheiros. Na edição do dia 23 de janeiro, a Gazeta de Notícias, sob o título "sindicato das carteiras", apontou que alguns dos funcionários da inspetoria perseguiam "aqueles que estão sob sua alçada, extorquindo-lhes dinheiro e cometendo toda a sorte de desatinos, tais como venda de exames de habilitação, cobrança de corretagens sobre as novas carteiras, etc." ${ }^{26}$

As denúncias tiveram efeito, pois no próprio dia 19 de janeiro, o Chefe de Polícia enviou um ofício ao $1^{\circ}$ Delegado Auxiliar determinando que respondesse "com toda brevidade possível, as referências que lhe são feitas na representação pública hoje pelo Jornal do Commercio". ${ }^{27}$ Um inquérito foi aberto para apurar as reclamações. Ao que tudo indica, esse escândalo, assim como as críticas que sofreu pela postura da Polícia de não ter evitado a greve, fez que João Brasil Silvado, chefe da instituição, pedisse sua demissão no dia 25 de janeiro.

Além de terem sido ouvidos sobre os abusos que vinham sendo cometidos pela inspetoria de veículos, os cocheiros e carroceiros tiveram outra vitória. No dia 20 de janeiro, o ministro da Justiça, Epitácio Pessoa, fez um despacho em que acatava todos os pedidos de mudança indicados na representação enviada pela Sociedade União Beneficente e Protetora dos Cocheiros.

No início de janeiro de 1904, estourou uma greve de cocheiros e carroceiros e o jornal O Paiz informou que os fundamentos da paralisação eram desconhecidos. Havia, segundo o periódico, versões desencontradas, "alguns atribuindo a fixação de um limite de peso máximo para as cargas das carroças, e 
outros, ao aumento do imposto sobre veículos, só mais tarde se soube que ela era originada pelo imposto votado pela municipalidade de $3 \$$ por cabeça de cada animal". ${ }^{28}$ Esse imposto foi promulgado pela Câmara Municipal em 1902, mas a cobrança só foi levada a cabo na administração do prefeito Pereira Passos.

O prefeito foi pessoalmente informar ao presidente da República que a greve havia sido motivada pelo imposto de $3 \$$ por animal, mas que ele deveria ser pago pelos proprietários das carroças, e não pelos carroceiros, cuja petição atendera. O periódico O Paiz indicou que os donos das carroças exigiam de seus empregados o desconto de $5 \$$ a $10 \$$ nos honorários mensais e "como os pobres dos cocheiros não se podem conformar com tão grande desconto em seus ordenados, os patrões aconselham a greve como meio de fazer a prefeitura recuar do seu propósito". ${ }^{29}$ Os patrões, portanto, foram tidos como os reais promotores da parede, tendo em vista que, ao taxarem indevidamente os empregados, teriam induzido o levante com o propósito de que o imposto deixasse de ser cobrado.

Os cocheiros e carroceiros reclamavam contra um imposto que não era de sua obrigação pagar, mas que de fato recaía sobre seus ombros, descontado de seus honorários. Ao que tudo indica, os patrões utilizaram os empregados para conseguir extinguir o imposto. Contudo, "o tiro saiu pela culatra", pois ao final da paralisação a taxa não foi revogada e os patrões tiveram de garantir que os trabalhadores não seriam onerados. Manipulados ou não, os cocheiros e carroceiros conseguiram atingir os seus objetivos com a greve, evitando o pagamento de taxas que não lhes eram devidas.

Há evidências de que, no caso de algumas paralisações, mesmo quando o principal motivo das mobilizações eram as questões salariais ou a diminuição da jornada de trabalho, os trabalhadores acreditavam estar lutando por direitos. A paralisação de dezembro de 1906, por exemplo, foi organizada pela Sociedade de Resistência dos Cocheiros, Carroceiros e Classes Anexas, uma associação criada no mesmo ano e que tinha como fim assegurar os direitos dos associados e obter melhores condições de trabalho por meios legais. A organização propunha uma tabela de reivindicações aos proprietários de veículos, como aumento da remuneração e redução das horas de trabalho.

Evaristo de Moraes era o advogado da Associação no período e também assumiu nesse conflito o papel de liderança na greve. Diante da polícia, o advogado se responsabilizou pela atitude dos grevistas. Ao reforçar a natureza legítima do movimento, ele garantiu que, contrariamente às denúncias que 
corriam, os grevistas "eram homens morigerados e trabalhadores, que procuravam pugnar pelos seus direitos". ${ }^{30}$

É necessário levar em conta que Moraes tentava ir ao encontro das expectativas da força policial ao colocar os grevistas como trabalhadores, que não pretendiam perturbar a ordem e sim lutar por direitos. Esses eram também os anseios do próprio tribuno, que tinha uma visão legalista. Como expôs Joseli Mendonça, ele fez questão de frisar que a referida parede ocorreria pacificamente e dentro das leis da República (Mendonça, 2007, p.108). Apesar dessas considerações, e tendo em vista que o legalismo dos advogados encontrou ressonância entre os cocheiros e carroceiros, também podemos pensar que quando lutavam por melhores salários e por menos horas de trabalho, os próprios trabalhadores acreditavam estar pugnando por direitos.

Em artigo intitulado "O dever supremo", publicado na edição de $1^{\circ}$ de abril de 1904 do jornal Brazil Operário, foram analisadas as causas "dos insucessos das greves ultimamente realizadas pelos operários desta Capital”, entre as quais possivelmente se incluíam algumas paralisações organizadas pelos cocheiros e carroceiros naquele ano. Segundo o periódico, as sociedades beneficentes deveriam contribuir com contingente para a formação de um centro de resistência, único meio de se "poder conseguir alguma coisa a bem da grande e sagrada causa”. Esse centro deveria ser responsável por realizar uma greve geral "para salvaguardar e garantir os direitos que porventura nos pretendessem sonegar". ${ }^{31}$

Seguindo esse raciocínio, o jornal considerou que representava insensatez e irreflexão pretender "conquistar direitos e nivelar interesses sem a formação de um Centro, só por meio de greves parciais, realizadas sem os recursos indispensáveis para a sua sustentação até a produção dos esperados efeitos". ${ }^{32}$ Sendo assim, por mais que se faça a crítica, a passagem permite verificar que os próprios trabalhadores entendiam que as paralisações tinham o intuito de conquistar direitos. A avaliação do Brazil Operário referia-se ao modo pelo qual as paredes deveriam ser conduzidas. Ao considerarmos essas greves como lutas unicamente econômicas, perdemos outras dimensões que poderiam ter para os sujeitos da época.

As diversas paralisações mencionadas ao longo do presente artigo permitem verificar alguns dos direitos requeridos pelos trabalhadores. É possível identificar que os cocheiros e carroceiros se viam como portadores de direitos quando, por exemplo, reclamavam a cobrança indevida de impostos, como na mobilização de janeiro de 1904, clamavam o direito de trabalhar diante das posturas municipais que objetivavam regular o serviço, caso da parede de 
fevereiro de 1876, ou ainda quando requisitavam melhores salários e jornadas de trabalho, o que ocorreu na mobilização de dezembro de 1906.

A parede, contudo, foi apenas uma das formas de expressão e estratégias de luta daquilo que os trabalhadores entendiam como seus direitos, os quais incluíam ainda os requerimentos enviados às autoridades competentes, por exemplo. Mas greves e requerimentos utilizavam linguagens bem diferentes. Nos requerimentos - que incluíam não só os trabalhadores, mas a população em geral, que também estava submetida à legislação sobre o transporte - a maneira encontrada para se fazerem ouvir foi, em sua maioria, a reelaboração do próprio discurso da instância a que se dirigiam. Dessa forma, como meio de conseguirem o que pleiteavam era importante, primeiramente, reconhecer a autoridade daqueles a quem enviavam seus pedidos. ${ }^{33}$ Além disso, era necessário se mostrarem merecedores de receber o que pediam, e, portanto, deveriam corresponder às expectativas que as classes dominantes tinham sobre eles, declarando-se, por exemplo, respeitadores da ordem ou pagadores de impostos. ${ }^{34}$ Além disso, o fato de afirmar ser cumpridora das obrigações imputadas fazia que a população se julgasse mais merecedora ainda de obter o que pedia.

A manifestação do que os trabalhadores acreditavam serem seus direitos, no caso dos requerimentos, expressava-se muitas vezes em tom de pedido; nas greves, no entanto, ganhava uma forma bem mais impositiva. As paralisações eram uma via de pressão mais direta e representavam uma demonstração de força no espaço público por parte dos trabalhadores. Nas greves dos cocheiros e carroceiros relacionadas a leis e regulamentos, em alguns casos os trabalhadores tentaram negociar com os órgãos competentes, porém, somente a paralisação de serviços essenciais para a cidade - como a recolha de lixo ou o transporte de mercadorias e pessoas - levou as autoridades a dialogarem com eles e atenderem suas demandas em quatro das cinco greves relativas à legislação e aos regulamentos.

Mesmo diante de um cenário de tanta precariedade e restrições aos direitos da população, como comentado no início do artigo, os cocheiros e carroceiros encontraram maneiras de lutar pelo que consideravam serem seus direitos e tentaram alargá-los. As greves indicam justamente que os trabalhadores envolvidos não foram meros expectadores e atuaram ativamente em relação a algumas decisões políticas que incidiam sobre seu ofício. Como firmou Marcelo Badaró Mattos, para "além de seu potencial nas reivindicações diretas aos patrões, as greves foram a principal forma de intervenção da classe trabalhadora na cena política brasileira, ao longo do século XX" (Mattos, 2007, p.422). 


\section{REFERÊNCIAS}

ARANTES, Erika Bastos. O Porto Negro: cultura e associativismo dos trabalhadores portuários no Rio de Janeiro na virada do XIX para o XX. Tese (Doutorado) ICHF, UFF. Niterói, 2010.

AZEVEDO, Elciene. A metrópole às avessas: cocheiros e carroceiros no processo de invenção da 'raça paulista'. In: et al. (Org.) Trabalhadores na cidade: cotidiano e cultura no Rio de Janeiro e em São Paulo, séculos XIX e XX. Campinas, SP: Ed. Unicamp, 2009.

CARVALHO, José Murilo de Carvalho. Cidadania no Brasil: o longo caminho. Rio de Janeiro: Civilização Brasileira, 2000.

CÓDIGO DE POSTURAS, leis, editais e resoluções da Intendência Municipal do Distrito Federal. Rio de Janeiro: Papelaria e Typographia Mont. Alverne, 1894.

FORTES, Alexandre. Os direitos, a lei e a ordem. Greves e mobilizações gerais na Porto Alegre da Primeira República. In: LARA, Silvia H.; MENDONÇA, Joseli Maria Nunes (Org.) Direitos e justiças no Brasil: ensaios de História Social. Campinas, SP: Ed. Unicamp, 2006.

GOMES, Ângela de Castro. A invenção do trabalhismo. Rio de Janeiro: Ed. FGV, 2005. LINHARES, Hermínio. Contribuição à história das lutas operárias. São Paulo: Alfa-Ômega, 1977.

LOBO, Eulália L. M.; STOTZ, Eduardo Navarro. Flutuações cíclicas da economia, condições de vida e movimento operário - 1880 a 1930. Revista do Rio de Janeiro, n.1, 1985.

MATTOS, Marcelo Badaró (Org.) Trabalhadores em greve, polícia em guarda: greves e repressão policial na formação da classe trabalhadora carioca. Rio de Janeiro: Bom Texto; Faperj, 2004.

MATTOS, Marcelo Badaró. As greves na trajetória da classe trabalhadora brasileira. In: JORNADA DO GT MUNDOS DO TRABALHO, 4. Anais... Porto Alegre: Anpuh/RS, 2007.

MENDONÇA, Joseli Maria Nunes. Evaristo de Moraes, tribuno da República. Campinas, SP: Ed. Unicamp, 2007.

RODRIGUES, Edgar. Trabalho e conflito: pesquisa histórica - 1900-1935. Rio de Janeiro: Arte Moderna, 1975.

\section{NOTAS}

${ }^{1}$ Este texto apresenta alguns aspectos desenvolvidos na tese de Doutorado defendida, em 2012, na Universidade Federal Fluminense (UFF), que contou com o financiamento do CNPq. 
${ }^{2} \mathrm{O}$ impacto das alterações instituídas em 1881 pode ser medido pelas estatísticas eleitorais: em 1872, os eleitores correspondiam a $13 \%$ da população livre; em 1886 , apenas $0,8 \%$ da população votou nas eleições parlamentares, significando um corte de aproximadamente 90\% do eleitorado (CARVALHO, 2000, p.39).

${ }^{3}$ Alguns autores já exploraram a ideia de que a greve foi uma importante via de luta por direitos. Esse foi o caso de Alexandre Fortes, que analisou as greves gerais realizadas em Porto Alegre na Primeira República (FORTES, 2006).

${ }^{4} 1906$ foi escolhido como recorte por ter sido o ano em que ocorreu a primeira greve organizada pela Sociedade de Resistência dos Cocheiros, Carroceiros e Classes Anexas, como também pela relevância no movimento operário, especialmente da cidade do Rio de Janeiro. Ocorreram diversos eventos como o relançamento da Gazeta Operária - importante porta-voz do movimento sindical, ligado aos cocheiros e carroceiros - e a fundação do Partido Operário Brasileiro - o primeiro formado com base nos sindicatos -, além da realização do Congresso Operário (MENDONÇA, 2007, p.106).

${ }^{5}$ Entre os textos que trataram das greves ocorridas no Rio de Janeiro, entre o final do século XIX e início do XX, é possível citar: RODRIGUES, 1975; LINHARES, 1977; LOBO; STOTZ, 1985; MATTOS, 2004.

${ }^{6}$ Ver, por exemplo: Jornal do Commercio, 22 fez. 1873, p.2.

${ }^{7}$ Jornal do Commercio, 27 nov. 1873, p.4.

${ }^{8}$ Jornal do Commercio, 29 nov. 1873, p.4. A grafia desta e de todas as citações da presente tese foi atualizada, embora se mantenha a pontuação e as palavras escritas com letra maiúscula no original.

${ }^{9}$ Gazeta de notícias, 15 fev. 1876, p.3.

${ }^{10}$ Ibidem.

${ }^{11}$ Revista Illustrada, 19 fev. 1876.

${ }^{12}$ Jornal do Commercio, 2 dez. 1890, p.1.

${ }^{13}$ Gazeta da Tarde, 2 dez. 1890, p.2.

${ }^{14}$ Diário de Notícias, 3 dez. 1890, p.1.

${ }^{15}$ O Diário de Notícias comentou um fato que havia sido estampado na primeira página dos principais jornais cariocas em julho de 1890: a morte de "uma criança, vitimada publicamente à Rua Gonçalves Dias, por uma dessas terríveis máquinas de destruição que se chamam bondes". Diário de Notícias, 14 jul. 1890, p.1.

${ }^{16}$ Diário de Notícias, 2 dez. 1890, p.1.

${ }^{17}$ Jornal do Commercio, 4 dez. 1890, p.1.

${ }^{18}$ Matéria reproduzida na Gazeta da Tarde, 10 dez. 1890, p.1.

${ }^{19}$ Gazeta de Notícias, 16 jan. 1900, p.1.

${ }^{20}$ Jornal do Brasil, 16 jan. 1900, p.1 
${ }^{21}$ Gazeta de Notícias, 16 jan. 1900, p.1. O ministro da Justiça, Epitácio Pessoa, considerou a greve injusta, entre outros motivos, porque o regulamento não mencionava a fotografia. Jornal do Brasil, 16 jan. 1900, p.1.

${ }^{22}$ Gazeta de Notícias, 16 jan. 1900, p.3.

${ }^{23}$ Jornal do Brasil, 16 jan. 1900, p.1. Erika Arantes apontou como o trabalhador do porto Antonio Mina se apresentava de diferentes formas nos depoimentos policiais, mostrando que essa podia sim ser uma estratégia da classe trabalhadora diante da constante investida policial (ARANTES, 2010).

24 "Estatuto da Sociedade União Beneficente e Protetora dos Cocheiros". Diário Oficial, nov. 1906.

${ }^{25}$ Jornal do Commercio, 19 jan. 1900, p.1.

${ }^{26}$ Gazeta de Notícias, 23 jan. 1900, p.1.

${ }^{27}$ Arquivo Nacional (AN), GIFI-6C46. 19 jan. 1900 - Gabinete do Chefe de Polícia.

${ }^{28}$ O Paiz, 10 jan. 1904, p.1.

${ }^{29}$ Ibidem.

${ }^{30}$ Correio da Manhã, 19 dez. 1906.

${ }^{31}$ Brazil Operário, 1 abr. 1904, p.1.

${ }^{32}$ Ibidem.

${ }^{33} \mathrm{Em} 22$ de julho de 1855, moradores e negociantes estabelecidos na Rua da Valla enviaram um abaixo-assinado à instituição camarária contra a proibição da circulação de veículos na rua. Eles afirmavam que vinham "com todo o respeito confiados na sabedoria, justiça e solicitude com que esta Ilustríssima Câmara, se há esforçado em prol dos melhoramentos e bem estar dos seus municípes”. AGCRJ, Códice 57.4.15, folha 239.

${ }^{34} \mathrm{Na}$ petição entregue pela Sociedade União Beneficente e Protetora dos Cocheiros ao ministro da Justiça após a greve de 1900, essa associação afirmou que tinha em seu seio um grande número de cocheiros e carroceiros e sabia "bem os intuitos ordeiros de que sempre esteve animada a classe". Jornal do Commercio, 19 jan. 1900, p.1.

Artigo recebido em 15 de agosto de 2012. Aprovado em 22 de outubro de 2014. 